\title{
Discussion to the Papers by Professor Chantraine et al. and Dr Stover et al.
} levels?

Professor A. Rossier (U.S.A.). Are there differences according to neurological

Professor Chantraine (Belgium). A tetraplegic has a low level for potassium but not for the other parameters.

PROFESSOR ROSSIER. We made a study which was parallel to this one with regard to aldosterone. What are your views about this?

Professor Chantraine. We did not test aldosterone.

Dr F. W. MeINECKe (Germany). One question to Dr Stover. We all know that there is a high incidence of recurrence of POA after operation. Did you do densitography before the operation to find out whether the bone is mature or not?

Dr STOVER (U.S.A.). We originally started this study for the same reason that you did, namely osteoporosis. We carried out densitometry with the camera and photonabsorption scanner on about I Io patients. There was really no difference in the placebo or the EHDP group. We had an emergency meeting in Denver to see whether it was the altitude, the water or something different in Denver as our studies did not parallel those of the original pilot study which was done in Detroit, which did seem to indicate that EHDP would be very useful in osteoporosis from any cause. Then the emphasis of the study shifted from osteoporosis to heterotopic ossification.

With regard to side effects, there have been no toxic effects at all and the side effects were exceedingly minimal. In trying to keep within the 12 months at my disposal I left a few things out of the paper. We did not measure hydroxy-proline but we measured practically every other thing which could be measured in the urine on a 24 -hour collection, including doing clearance tests, etc.

Regarding the radio-isotope bone scans, I agree with Dr Rossier that is probably an important method of determining bone maturity.

MR T. MCSweENEY (G.B.). There is a certain similarity between this topic and our subject yesterday, namely deep venous thrombosis. I think the incidence must vary tremendously from country to country and indeed perhaps seasonally. I would, for instance, not contemplate putting any of our patients on EHDP bearing in mind our 5 per cent unfortunate incidence. As a surgeon I fear from these two excellent papers that I may be put out of business by the diphosphosates, which would please me very greatly, because as we all know, the treatment of this condition is very far from satisfactory. There are two small points of interest. First, in the last 8 or 9 years we have been putting a free fat graft in the dead space after POA removal, and we believe in fact that bone is not usually deposited in this gap between the area of excision. We take a slightly different view from Hardy and Dickson in the sense that we attempt as complete as possible the removal of the bone, in other words, we do not do a wedge resection. The second point is that in massive POA hip there is a problem which I have met on three occasions as shown in some of Dr Stover's slides. It is largely lateral, on other occasions it is largely medial and on three occasions I have found the main vessel going right through the mass of para-articular ossification. We have learnt our lesson now and in each case before surgery, if surgery is contemplated and if the masses are medial, we carry out a preoperative arteriogram. Curiously enough,' to unblock the main vessel if it is going through the masses is not as hazardous as one may think, but it does add to the whole length of the procedure and can produce rather embarrassing moments.

DR H. FRANKel (G.B.). In addition to allowing time between the spinal injury and the operation because of the controversy we have had about surgical treatment and its successes, it would be helpful if we knew the time between the first onset of heterotopic ossification and the last sign of activity. If we had this classified for any operative procedure, I think we would get very much closer to answering the questions which have been raised by the Swiss.

Dr STOVER. I think this is important. The first two patients that I showed on this 
slide had their bone within 2 to 3 months. Now I cannot pin-point it exactly because some of the patients had gone home, or were in another hospital at the time of its development.

DR L. Michaelis (G.B.). Only a surgeon who has had to do excision of bone in these circumstances can really be sufficiently grateful for anything which will prevent them from having to deal with this. Let me now give you a few figures, when last going through our material I looked at the last thousand patients treated at Stoke Mandeville and I found that only 5 per cent had heterotopic ossification of any clinically important degree and only 4.5 per cent had ankylosis. Therefore, at least in Stoke Mandeville the incidence was very low. None of us in any Centre will be able to use sufficiently large numbers to prove anything. May I suggest perhaps that with the aid of the new centralising office of Dr Young, Stover and Hart, one might organise a survey on similar lines from all American Centres, and in this country, Stoke Mandeville, Sheffield and Oswestry might pool resources and really get numbers which will, if properly treated and all on the same principles, begin to prove something. The second point I want to make is do not draw any conclusions 9 months after injury. That is much too early whether you have a success with the new drug or whether you have a success with operations. Do not assess it before 4 years after you have done it because there may be a recurrence during that time. 